\title{
Conventional and alternative preventive treatments in the first stages of schizophrenia
}

\author{
Danijela Piskulic* \\ Barnaby Nelson \\ Mario Alvarez-Jimenez \\ Patrick McGorry
}

Orygen, The National Centre of Excellence

in Youth Mental Health, Centre for Youth

Mental Health, University of Melbourne

AUSTRALIA

\begin{abstract}
Background and Objectives: Schizophrenia is a progressive disorder that moves through multiple stages starting from non-specific risk factors to at-risk mental state (ARMS) (also known as ultra-high risk of psychosis or UHR) to first episode of psychosis (FEP) to chronic course marred by frequent relapses and varying degrees of disability. In order to prevent a deteriorating course, treatments designed to address and possibly even correct the abnormal neuronal system functioning and psychosocial deficits need to be implemented early before potentially irreversible and maladaptive changes take place.

Methods: A literature search was conducted in the electronic databases Pub-Med and MEDLINE for relevant empirical and review articles published in peer reviewed journals.

Results: The review of literature suggests that a range of pharmacological and psychosocial interventions are being used and trialled in treatment of early stages of schizophrenia with varying degrees of success.

Conclusions: There is a variety of therapies for schizophrenia ranging in scope from improving symptom profiles to functional recovery and a good rationale for their use early in the course of illness. Treatments that focus on integrating pharmacological, psychological and psychosocial interventions with a strong evidence base for effectiveness need to be integrated for the best chance to avert or hinder schizophrenia. Schizophrenia research is moving towards a notion that early intervention can interact with existing and intact neuroplasticity mechanisms that can be harnessed in an adaptive manner to promote healthier neural system functioning and increased stress resiliency, which will in turn lead to symptom reduction and functional recovery.
\end{abstract}

Received: 17 February 2015

Revised: 25 February 2015

Accepted: 4 March 2015 


\section{Introduction}

Schizophrenia is a syndrome that includes signs and symptoms of unknown aetiology ${ }^{1}$. The early course of schizophrenia has been found to predict longitudinal course of the illness ${ }^{2,3}$. Early intervention services, introduced in the 1990s, have been established to reduce treatment delay and provide phase specific care ${ }^{4,5}$. Based on the staging model of mental illness ${ }^{6}$, schizophrenia is a progressive disorder that moves through multiple stages starting from non-specific risk factors to atrisk mental state (ARMS) (also known as ultra-high risk of psychosis or UHR) to first episode of psychosis (FEP) to chronic course marred by frequent relapses and varying degrees of disability. As a syndrome, schizophrenia is characterised by FEP whereby sufficient symptoms are present to differentiate an illness ${ }^{7}$. This corresponds to the concept of "early period" introduced by Birchwood and colleagues $^{8}$, which focuses on the ARMS and FEP and implies that it is imperative to intervene during this "critical period" and thereby alter the early course of illness by lowering morbidity, disability and cost associated with schizophrenia ${ }^{9,10}$. This represents a paradigm shift from management of long term disability to an expectation that interventions in the early stages of schizophrenia will result in improved psychosocial outcomes.

Intervention research in the early stages of schizophrenia now focuses on not only treatments of existing symptomatology and disability but also on reducing duration of untreated psychosis and prevention of psychotic relapse. This shift has been driven by phase specific research, both retrospective and prospective, that indicates dysfunction in a number of brain systems in schizophrenia prodrome and ARMS. One of the largest longitudinal studies of volumetric brain changes in schizophrenia over time reported decreases in multiple grey and white matter regions, which were most evident two years following $\mathrm{FEP}^{11}$. Loss of brain volume was similarly noted in ARMS individuals who transitioned to psychosis compared to those who did not transition and healthy volunteers ${ }^{12}$. That is, the brain and psychosocial functioning in the early stages of schizophrenia are compromised. In order to prevent a deteriorating course, treatments designed to address and possibly even correct the abnormal neuronal system functioning and psychosocial deficits need to be implemented early before potentially irreversible and maladaptive changes take place ${ }^{5,6,13}$.

To date, a number of randomised controlled trials (RCTs) testing a range of psychological, pharmacological, nutritional and multicomponent psychosocial treatments have been conducted. The current paper presents an overview of most utilised and researched treatments, both conventional and alternative, in the early stages of schizophrenia with an emphasis on the FEP.

\section{Methods}

A literature search was conducted in the electronic databases Pub-Med and MEDLINE for relevant empirical and review articles published in peer reviewed journals using the following keywords: early schizophrenia, early psychosis, ultra-high risk, clinical high risk, treatment, therapy. Selected articles were further cross-checked for additional references. Chosen articles were reviewed for information regarding treatment initiatives, which are summarised in the following sections. Treatments were defined as deliverable interventions aiming to relieve psychotic symptomatology or to improve functional outcomes in early schizophrenia ${ }^{14}$. 


\section{Indicated and novel pharmacological treatments}

Current biological treatment options for established schizophrenia have predominantly centred on the dopamine theory and treatment with dopamine antagonists such as antipsychotics. In the ARMS, antipsychotics are generally avoided and are instead reserved for later stages of psychotic illness. In FEP, antipsychotics are used as the first line treatment to mitigate psychotic symptoms. The response rate is reportedly in the range of $40-90 \% 15,16,17,18$ with time to response ranging from one to ten weeks of treatment ${ }^{17,18}$. Despite this variability, patients with FEP show positive treatment outcomes as a result of antipsychotic treatment compared to those with the chronic course of illness ${ }^{18}$. Secondgeneration antipsychotics (SGAs) reportedly have superior efficacy in relapse prevention and in reducing psychotic symptoms compared to first generation antipsychotics (FGAs) ${ }^{16,19}$. However, this advantageous efficacy is not as clear when individual SGAs are compared to individual FGAs ${ }^{19}$.

Besides side-effects, antipsychotics are not efficacious in treatment of negative and cognitive symptoms of schizophrenia, or psychosocial functioning, which has triggered a search for alternative pharmacological therapies. There is now a body of evidence to support a role for both inflammation and oxidative stress in the pathophysiology of psychotic disorders ${ }^{20,21}$. Environmental factors such as inflammation, obstetric complications, viral infections and stress have been associated with an increase in oxidative stress and are also considered risk factors for schizophrenia $^{22}$. Oxidative stress, a state where the levels of available antioxidants is reduced, or the levels of oxidative species is increased, is well documented in schizophrenia and re- lated psychoses ${ }^{20}$. Furthermore, there is consistent evidence of increased blood concentrations of inflammatory cytokines in patients with schizophrenia ${ }^{23}$. Given that inflammatory abnormalities are present in drug-naive individuals in early schizophrenia, which are comparable to those reported in patients with the chronic course of the disorder, suggests an association independent of antipsychotic medication ${ }^{24}$. Inflammation and oxidative stress also reciprocally induce each other in a positive feedback manner ${ }^{25}$. Recent research suggests that the supplementation with omega-3 poly unsaturated fatty acids (PUFAs) appears to be a promising treatment in the early stages of schizophrenia ${ }^{26,27}$. In the ARMS, omega-3 PUFAs were effective in reducing transition to psychosis ${ }^{26}$. According to a recent Cochrane Review, doses of antipsychotics can be reduced in schizophrenia patients who are on omega-3 supplements ${ }^{28}$. Although omega-3 supplements are promising across all stages of illness evidence to date suggests that they may be most useful in the ARMS where they may have a neuroprotective role ${ }^{26}$. Several large clinical trials are currently being conducted to determine the mechanism and the role that omega-3 PUFAs play in the prevention and treatment of schizophrenia. One of the trials is being conducted in a large ARMS cohort by our group (ANZ CTR ID: ACTRN12608000475347).

Additionally, evidence suggests that aspirin may also be effective in treating psychotic symptoms ${ }^{29}$. Besides its anti-inflammatory and antioxidant properties, aspirin has been shown to have antidepressant effects in preclinical studies and reduces risk of depression in epidemiological studies ${ }^{30,31}$. Given that depression is a common feature in all phases of schizophrenia, these antidepressant effects provide further rationale for using aspirin. Low-dose aspirin has been shown to be both anti-inflammatory and neu- 
roprotective in humans and animal models ${ }^{32}$ Aspirin can also reduce oxidative stress and protect against oxidative damage $\mathrm{e}^{33}$ and it has been reported as a safe, tolerable and less time-consuming treatment option. Studies on efficacy of aspirin symptom management early in the course of schizophrenia are just starting, and to date there is one registered trial of aspirin in an ARMS sample (ClinicalTrials.gov ID: NCT02047539).

\section{Psychological therapies}

Psychological therapies in all phases of schizophrenia have aimed to target symptoms of illness, such as positive and negative symptoms, as well as cognitive deficits ${ }^{7}$. In later phases of illness, they are used as adjuncts to pharmacological treatments rather as standalone treatments. However, recent evidence suggests that some psychological treatments such as cognitive behavioural therapy (CBT) may be effective on their own ${ }^{34,35}$. A range of psychological therapies have been developed over the years of which CBT and family interventions have been recommended in clinical guidelines for early schizophrenia ${ }^{36}$. Additionally, there has been a rise in demand for cognitive remediation in this stage of illness as there are reports that some forms of it are beneficial. Psychological therapies are benign treatments used as first line interventions in the ARMS, and to a large extent in FEP.

CBT, which is based on cognitive models of psychosis, has been implemented in all stages of schizophrenia. This model posits that dysfunctional interpretations of anomalous experiences contribute, against a background of pre-existing biopsychosocial vulnerability, to the emergence and maintenance of psychotic symptoms ${ }^{37,38}$. Results from trials of CBT in the ARMS and early schizo- phrenia suggest that the therapy is moderately effective in reducing transitions to psychosis $^{39,40,41}$, reducing relapse rates ${ }^{42}$, speeding recovery ${ }^{43}$, reducing subclinical and clinical positive symptom severity $39,40,44$ and improving perceived quality of life ${ }^{45}$. However, durability of CBT in absence of continued treatment is unclear with reports of both durable effects in the $\mathrm{ARMS}^{39}$ and lack thereof in $\mathrm{FEP}^{42,44,45}$. Lack of sustained effect of CBT may in part be due to the limited duration of treatment and more longitudinal trials with longer duration of CBT treatment are therefore needed ${ }^{7,42}$.

Family interventions have likewise been extensively researched, and tend to range from traditional family therapy to psychoeducational therapies ${ }^{7}$. Based on this research, there is evidence for a range of benefits of family therapy in FEP and more advance stages of illness, such as increased medication compliance and reduced hospitalisation as well as relapse $\mathrm{e}^{46,47}$. However, effectiveness of family therapy in the ARMS is yet to be established and a group of US researchers is currently trialling this ${ }^{48,49}$. This is especially important given that patients in the ARMS and FEP tend to have greater interaction with their families compared to patients with a chronic course of the disorder who are generally older, which means that the effect of family therapy early in the illness may be stronger?

\section{Cognitive remediation therapy}

Given a wide range of cognitive deficits across all stages of schizophrenia, including the ARMS, compared to healthy persons and other psychiatric groups, there has been a rise in demand for treatments that directly target cognitive dysfunction. Cognitive deficits are strongly related to poor functioning in areas of 
work, social relationships and independent living ${ }^{50,51}$, which is why there is a notion that improving cognition and the ability to learn may enable individuals to engage in broader rehabilitation efforts and hence improve their functional outcomes ${ }^{52}$. Initiatives targeting cognition, cognitive remediation treatments (CRT), are divided into cognition-enhancing and compensatory approaches. While cognition-enhancing approaches have been designed to improve specific abilities in different cognitive domains (e.g. learning, memory, attention) through a set of specified training modules ${ }^{50}$, compensatory approaches attempt to bypass cognitive impairments and teach strategies to "compensate" for these impairments by relying on environmental aids or similar processes ${ }^{50,53,54}$. To date, the success of both cognition-enhancing and compensatory methods at improving cognition and functional outcomes of people with schizophrenia has been encouraging. Additionally, given that people in early schizophrenia experience impairments in cognition and functioning similar or equivalent to those evidenced by individuals in the later stages of their illness, it is thought beneficial to implement CRT as early in the course of illness as possible. Only a handful of studies examining efficacy and durability of CRT in the ARMS 55,56 and FEP $^{53,54,57,58}$ have been done to date with early evidence suggesting favourable effects.

\section{Psychosocial therapies}

Psychosocial therapies have been designed to aid functional recovery by targeting areas implicated in the development of disability, such as impaired social and role functioning, but which are not directly linked with symptoms of illness ${ }^{7}$. They have been reported to improve treatment adherence and promote bet- ter occupational and social functioning in established schizophrenia ${ }^{59,60}$. Given that schizophrenia typically occurs in late adolescence and early adulthood, which are critical phases of life for social and occupational development, these areas of functioning are often the first to show marked decrease from premorbid levels. Despite wanting to stay at school or work, almost half of people in early schizophrenia are out of school or unemployed ${ }^{7,61}$.

It is now widely accepted that functional recovery is just as important as symptomatic recovery. Functional disability is the most costly aspect of psychotic illness and functional recovery is valued by patients above symptomatic recovery ${ }^{62}$. Therapies such as vocational rehabilitation, including return to study for younger patients, have been designed to minimise functional disability and improve long-term occupational functioning. The most evidence-based model of vocational recovery broadly, and supported employment specifically, is the Individual Placement and Support (IPS) model. Studies of IPS in early schizophrenia have reported achieved employment or education rates as high as $85 \%{ }^{63,64}$. However, maintaining occupational roles has been identified as a challenge in this cohort suggesting that other factors, such as cognitive function, are involved in successful vocational rehabilitation ${ }^{65}$. Therefore, there are now recommendations for adjunctive interventions to vocational therapy ${ }^{65,66}$ in order to enhance its effects.

Reflective of the technological developments and their utility in other areas of health, internet and mobile based therapies are being developed for treatment delivery in all stages of schizophrenia ${ }^{67}$. Given that young people are amongst the biggest users of these technologies, it is intuitive that interventions are turning to these resources for support. Preliminary research in this area to date has found beneficial effects of computer and mo- 
bile phone based psychoeducation on rate of relapse, hospitalization, socialisation and medication adherence of patients with established schizophrenia ${ }^{59,60}$. A new wave of research on internet based therapies is currently underway, and a recent study by our group has shown it to be feasible and beneficial in terms of perceived social connectedness and empowerment in $\mathrm{FEP}^{68}$. To our knowledge, there is no current empirical evidence exploring appropriate vocational interventions for the ARMS although similar principles are likely to be relevant ${ }^{36}$.

\section{Conclusions}

A variety of therapies now exist for schizophrenia ranging in scope from improving symptom profiles to functional recovery, and there is a good rationale for their use early in the course of illness. Such therapies in early schizophrenia are qualitatively different from preventing future cases of the disorder or from early symptom identification, but may nevertheless help reduce morbidity in those who continue through to the more chronic course $^{69}$. Combining therapies such as psychological or psychosocial with novel pharmacological treatments is an approach that needs to be evaluated further as different treatments, sequences and durations of therapy may be needed for sustained benefits ${ }^{70,71}$. Longitudinal follow-up studies suggest that most of treatment benefits early in the course of schizophrenia are seen in the first 2 years and are generally not sustained at the 5 year follow-up ${ }^{70}$. That said, it may be that a combination of longer interventions administered longitudinally, over the illness course and as a part of standard therapy, is needed to produce the most efficacious, long term benefits. After all, treatment development at all stages of schizophrenia is undergoing a shift from conceptualising schizophrenia as a neurodegenerative disease with an inevitably poor outcome to a manageable disease. Treatments that focus on integrating pharmacological, psychological and psychosocial interventions, which have a strong evidence base for effectiveness, need to be integrated for the best chance to avert or hinder schizophrenia ${ }^{1}$. A perspective that early intervention can interact with existing and intact neuroplasticity mechanisms that can be harnessed in an adaptive manner to promote healthier neural system functioning and increased stress resiliency, which will lead to symptom reduction and functional recovery, is becoming increasingly popular ${ }^{13}$.

\section{References}

1. Insel TR. Rethinking schizophrenia. Nature. 2010; 468(7321): 187-93

2. Wiersma D, Nienhuis FJ, Slooff CJ, Giel R. Natural course of schizophrenic disorders: A 15-year followup of a Dutch incidence cohort. Schizophr Bull. 1998; 24(1): 75-85.

3. Harrison G, Gunnell D, Glazebrook C, Page K, Kwiecinski R. Association between schizophrenia and social inequality at birth: Case-control study. Br J Psychiatry. 2001; 179: $346-50$

4. McGorry PD, Singh BS. Schizophrenia: Risk and possibility. In: Raphael B and Burrows GD, editor. Handbook of Preventative Psychiatry. Amsterdam, Netherlands: Elsevier. 1995. p. 492-514.

5. Henry LP, Amminger GP, Harris MG, Yuen HP, Harrigan SM, Prosser AL, et al. The EPPIC follow-up study of first-episode psychosis: Longer-term clinical and functional outcome 7 years after index admission. J Clin Psychiatry. 2010; 71(6): 716-28.

6. McGorry PD, Hickie IB, Yung AR, Pantelis C, Jackson HJ. Clinical staging of psychiatric disorders: A heuristic framework for choosing earlier, safer and more effective interventions. Aust N Z J Psychiatry. 2006; 40(8): 616-22.

7. Killackey E. Psychosocial and psychological interventions in early psychosis: Essential elements for recovery. Early Interv Psychiatry. 2009; 3 Suppl 1: S17-21. 
8. Birchwood M, Todd P, Jackson C. Early intervention in psychosis. The critical period hypothesis. Br J Psychiatry Suppl. 1998; 172(33): 53-9.

9. Zeidler J, Slawik L, Fleischmann J, Greiner W. The costs of schizophrenia and predictors of hospitalisation from the statutory health insurance perspective. Health Econ Rev. 2012; 2(1): 9 .

10. Petersen L, Nordentoft M, Jeppesen P, Ohlenschaeger J, Thorup A, Christensen TO, et al. Improving 1-year outcome in first-episode psychosis: OPUS trial. Br J Psychiatry Suppl. 2005; 48: s98-103.

11. Andreasen NC, Nopoulos P, Magnotta V, Pierson R, Ziebell S, Ho BC. Progressive brain change in schizophrenia: A prospective longitudinal study of first-episode schizophrenia. Biol Psychiatry. 2011; 70(7): 672-9.

12. Ziermans TB, Schothorst PF, Schnack HG, Koolschijn PC, Kahn RS, van Engeland H, et al. Progressive structural brain changes during development of psychosis. Schizophr Bull. 2012; 38(3): 519-30.

13. Fisher M, Loewy R, Hardy K, Schlosser D, Vinogradov $\mathrm{S}$. Cognitive interventions targeting brain plasticity in the prodromal and early phases of schizophrenia. Annu Rev Clin Psychol. 2013;9:435-63.

14. Liu P, Parker AG, Hetrick SE, Callahan P, de Silva S, Purcell R. An evidence map of interventions across premorbid, ultra-high risk and first episode phases of psychosis. Schizophr Res. 2010; 123(1): 37-44.

15. Agid O, Arenovich T, Sajeev G, Zipursky RB, Kapur $\mathrm{S}$, Foussias G, et al. An algorithm-based approach to firstepisode schizophrenia: Response rates over 3 prospective antipsychotic trials with a retrospective data analysis. J Clin Psychiatry. 2011; 72(11): 1439-44.

16. Boter H, Peuskens J, Libiger J, Fleischhacker WW, Davidson M, Galderisi S, et al. Effectiveness of antipsychotics in first-episode schizophrenia and schizophreniform disorder on response and remission: An open randomized clinical trial (EUFEST). Schizophr Res. 2009; 115(2-3): 97-103.

17. Emsley R, Rabinowitz J, Medori R. Time course for antipsychotic treatment response in first-episode schizophrenia. Am J Psychiatry. 2006; 163(4): 743-5.

18. Schennach-Wolff R, Seemuller FH, Mayr A, Maier W, Klingberg S, Heuser I, et al. An early improvement threshold to predict response and remission in first-episode schizophrenia. Br J Psychiatry. 2010; 196(6): 460-6.

19. Alvarez-Jimenez M, Parker AG, Hetrick SE, McGorry PD, Gleeson JF. Preventing the second episode: A systematic review and meta-analysis of psychosocial and pharmacological trials in first-episode psychosis. Schizophr Bull. 2011; 37(3): 619-30.
20. Flatow J, Buckley P, Miller BJ. Meta-analysis of oxidative stress in schizophrenia. Biol Psychiatry. 2013; 74(6): 400-9.

21. Fineberg AM, Ellman LM. Inflammatory cytokines and neurological and neurocognitive alterations in the course of schizophrenia. Biol Psychiatry. 2013; 73(10): 951-66.

22. O'Donnell P. Cortical interneurons, immune factors and oxidative stress as early targets for schizophrenia. Eur J Neurosci. 2012; 35(12): 1866-70.

23. Miller BJ, Buckley P, Seabolt W, Mellor A, Kirkpatrick B. Meta-analysis of cytokine alterations in schizophrenia: Clinical status and antipsychotic effects. Biol Psychiatry. 2011; 70(7): 663-71.

24. Cazzullo CL, Sacchetti E, Galluzzo A, Panariello A, Colombo F, Zagliani A, et al. Cytokine profiles in drug-naive schizophrenic patients. Schizophr Res. 2001; 47(2-3): 293-8.

25. Bitanihirwe BK, Woo TU. Oxidative stress in schizophrenia: An integrated approach. Neurosci Biobehav Rev. 2011; 35(3): 878-93.

26. Amminger GP, Schafer MR, Papageorgiou K, Klier CM, Cotton SM, Harrigan SM, et al. Long-chain omega-3 fatty acids for indicated prevention of psychotic disorders: A randomized, placebo-controlled trial. Arch Gen Psychiatry. 2010; 67(2): 146-54.

27. Keller WR, Kum LM, Wehring HJ, Koola MM, Buchanan RW, Kelly DL. A review of anti-inflammatory agents for symptoms of schizophrenia. J Psychopharmacol. 2013; 27(4): 337-42.

28. Joy CB, Mumby-Croft R, Joy LA. Polyunsaturated fatty acid supplementation for schizophrenia. Cochrane Database Syst Rev. 2006(3): CD001257. Review.

29. Laan W, Grobbee DE, Selten JP, Heijnen CJ, Kahn RS, Burger H. Adjuvant aspirin therapy reduces symptoms of schizophrenia spectrum disorders: Results from a randomized, double-blind, placebo-controlled trial. J Clin Psychiatry. 2010; 71(5): 520-7.

30. Brunello N, Alboni S, Capone G, Benatti C, Blom JM, Tascedda F, et al. Acetylsalicylic acid accelerates the antidepressant effect of fluoxetine in the chronic escape deficit model of depression. Int Clin Psychopharmacol. 2006; 21(4): 219-25.

31. Pasco JA, Jacka FN, Williams LJ, Henry MJ, Nicholson GC, Kotowicz MA, et al. Clinical implications of the cytokine hypothesis of depression: The association between use of statins and aspirin and the risk of major depression. Psychother Psychosom. 2010; 79(5): 323-5.

32. Berk M, Dean O, Drexhage H, McNeil JJ, Moylan S, O'Neil A, et al. Aspirin: A review of its neurobiological properties and therapeutic potential for mental illness. BMC Med. 2013; 11:74. Review. 
33. Ayyadevara S, Bharill P, Dandapat A, Hu C, Khaidakov M, Mitra S, et al. Aspirin inhibits oxidant stress, reduces age-associated functional declines, and extends lifespan of Caenorhabditis elegans. Antioxid Redox Signal. 2013; 18(5): 481-90.

34. Morrison AP, Turkington D, Pyle M, Spencer H, Brabban A, Dunn G, et al. Cognitive therapy for people with schizophrenia spectrum disorders not taking antipsychotic drugs: A single-blind randomised controlled trial. Lancet. 2014; 383(9926): 1395-403.

35. Morrison AP, Hutton P, Wardle M, Spencer H, Barratt $\mathrm{S}$, Brabban A, et al. Cognitive therapy for people with a schizophrenia spectrum diagnosis not taking antipsychotic medication: An exploratory trial. Psychol Med. 2012; 42(5): 1049-56.

36. Health OY. The Australian Clinical Guidelines for early Psychosis. Melbourne: Orygen Youth Health. 2008.

37. Garety PA, Kuipers E, Fowler D, Freeman D, Bebbington PE. A cognitive model of the positive symptoms of psychosis. Psychol Med. 2001; 31(2): 189-95.

38. Morrison A. The interpretation of intrusions in psychosis: An integrative cognitive approach to hallucinations and delusions. Behav Cogn Psychother. 2001; 29: 257-76.

39. Morrison AP, French P, Parker S, Roberts M, Stevens $\mathrm{H}$, Bentall RP, et al. Three-year follow-up of a randomized controlled trial of cognitive therapy for the prevention of psychosis in people at ultrahigh risk. Schizophr Bull. 2007;33(3):682-7.

40. van der Gaag M, Nieman DH, Rietdijk J, Dragt S, Ising HK, Klaassen RM, et al. Cognitive behavioral therapy for subjects at ultrahigh risk for developing psychosis: A randomized controlled clinical trial. Schizophr Bull. 2012; 38(6): 1180-8.

41. Hutton P, Taylor PJ. Cognitive behavioural therapy for psychosis prevention:A systematic review and meta-analysis. Psychol Med. 2014; 44(3): 449-68.

42. Gleeson JF, Cotton SM, Alvarez-Jimenez M, Wade D, Gee D, Crisp K, et al. A randomized controlled trial of relapse prevention therapy for first-episode psychosis patients: Outcome at 30-month follow-up. Schizophr Bull. 2013; 39(2): 436-48.

43. Lewis S, Tarrier N, Haddock G, Kinderman P, Kingdon $\mathrm{D}$, Siddle R, et al. Randomised controlled trial of cognitive behavioural therapy in early schizophrenia: Acute-phase outcomes. Br J Psychiatry Suppl. 2002; 181(s43): s91-s7.

44. Tarrier N, Lewis S, Haddock G, Bentall R, Drake R, Kinderman $\mathrm{P}$, et al. Cognitive-behavioural therapy in firstepisode and early schizophrenia. 18-month follow-up of a randomised controlled trial. Br J Psychiatry. 2004; 184: 231-9.
45. Jackson HJ, McGorry PD, Killackey E, Bendall S, Allott K, Dudgeon P, et al. Acute-phase and 1-year follow-up results of a randomized controlled trial of CBT versus Befriending for first-episode psychosis: The ACE project. Psychol Med. 2008; 38(5): 725-35.

46. Pharoah F, Mari J, Rathbone J, Wong W. Family intervention for schizophrenia. Cochrane Database Syst Rev. 2006(4):CD000088. Review.

47. Excellence NIfHaC. Schizophrenia (Update): Full Guideline. London: National Institute for Health and Clinical Excellence. 2008.

48. O’Brien MP, Zinberg JL, Bearden CE, Daley M, Niendam TA, Kopelowicz A, et al. Psychoeducational multi-family group treatment with adolescents at high risk for developing psychosis. Early Interv Psychiatry. 2007; 1(4): 325-32.

49. Schlosser DA, Miklowitz DJ, O’Brien MP, De Silva SD, Zinberg JL, Cannon TD. A randomized trial of family focused treatment for adolescents and young adults at risk for psychosis: Study rationale, design and methods. Early Interv Psychiatry. 2012; 6(3): 283-91.

50. McGurk SR, Twamley EW, Sitzer DI, McHugo GJ, Mueser KT. A meta-analysis of cognitive remediation in schizophrenia. Am J Psychiatry. 2007; 164(12): 1791-802.

51. Kern RS, Liberman RP, Becker DR, Drake RE, Sugar $\mathrm{CA}$, Green MF. Errorless learning for training individuals with schizophrenia at a community mental health setting providing work experience. Schizophr Bull. 2009; 35(4): 807-15.

52. Green MF. New possibilities in cognition enhancement for schizophrenia. Am J Psychiatry. 2009; 166(7): 749-52.

53. Eack SM, Hogarty GE, Cho RY, Prasad KM, Greenwald DP, Hogarty SS, et al. Neuroprotective effects of cognitive enhancement therapy against gray matter loss in early schizophrenia: Results from a 2-year randomized controlled trial. Arch Gen Psychiatry. 2010; 67(7): 674-82.

54. Eack SM, Greenwald DP, Hogarty SS, Keshavan MS. One-year durability of the effects of cognitive enhancement therapy on functional outcome in early schizophrenia. Schizophr Res. 2010; 120(1-3): 210-6.

55. Rauchensteiner S, Kawohl W, Ozgurdal S, Littmann E, Gudlowski Y, Witthaus H, et al. Test-performance after cognitive training in persons at risk mental state of schizophrenia and patients with schizophrenia. Psychiatry Res. 2011; 185(3): 334-9.

56. Piskulic D, Barbato M, Liu L, Addington J. Pilot study of cognitive remediation therapy on cognition in young people at clinical high risk of psychosis. Psychiatry Res. 2015; 225(1-2): 93-8. 
57. Ueland T, Rund BR. Cognitive remediation for adolescents with early onset psychosis: A 1-year follow-up study. Acta Psychiatr Scand. 2005; 111(3): 193-201.

58. Wykes T, Newton E, Landau S, Rice C, Thompson N, Frangou S. Cognitive remediation therapy (CRT) for young early onset patients with schizophrenia: An exploratory randomized controlled trial. Schizophr Res. 2007; 94(1-3): 221-30.

59. Spaniel F, Vohlidka P, Hrdlicka J, Kozeny J, Novak T, Motlova L, et al. ITAREPS: Information technology aided relapse prevention programme in schizophrenia. Schizophr Res. 2008; 98(1-3): 312-7.

60. Granholm E, Ben-Zeev D, Link PC, Bradshaw KR, Holden JL. Mobile Assessment and Treatment for Schizophrenia (MATS): A pilot trial of an interactive text-messaging intervention for medication adherence, socialization, and auditory hallucinations. Schizophr Bull. 2012; 38(3): 414-25.

61. Killackey E. Something for everyone: Employment interventions in psychotic illness. Acta Neuropsychiatr. 2008; 20: 277-9.

62. Iyer SN, Mangala R, Anitha J, Thara R, Malla AK. An examination of patient-identified goals for treatment in a first-episode programme in Chennai, India. Early Interv Psychiatry. 2011; 5(4): 360-5.

63. Killackey E, Jackson HJ, McGorry PD. Vocational intervention in first-episode psychosis: Individual placement and support v. treatment as usual. Br J Psychiatry. 2008; 193(2): 114-20.

64. Nuechterlein KH, Subotnik KL, Turner LR, Ventura J, Becker DR, Drake RE. Individual placement and support for individuals with recent-onset schizophrenia: Integrating supported education and supported employment. Psychiatr Rehabil J. 2008; 31(4): 340-9.

65. Allott KA, Cotton SM, Chinnery GL, Baksheev GN, Massey J, Sun P, et al. The relative contribution of neurocognition and social cognition to 6-month vocational out- comes following Individual Placement and Support in firstepisode psychosis. Schizophr Res. 2013; 150(1): 136-43.

66. McGurk SR, Mueser KT, DeRosa TJ, Wolfe R. Work, recovery, and comorbidity in schizophrenia: A randomized controlled trial of cognitive remediation. Schizophr Bull. 2009; 35(2): 319-35.

67. Alvarez-Jimenez M, Alcazar-Corcoles MA, Gonzalez-Blanch C, Bendall S, McGorry PD, Gleeson JF. Online, social media and mobile technologies for psychosis treatment: A systematic review on novel user-led interventions. Schizophr Res. 2014; 156(1): 96-106.

68. Alvarez-Jimenez M, Bendall S, Lederman R, Wadley G, Chinnery G, Vargas S, et al. On the HORYZON: Moderated online social therapy for long-term recovery in first episode psychosis. Schizophr Res. 2013; 143(1): 143-9.

69. Wyatt RJ, Henter I. Rationale for the study of early intervention. Schizophr Res. 2001; 51(1): 69-76.

70. Bertelsen M, Jeppesen P, Petersen L, Thorup A, Ohlenschlaeger J, le Quach P, et al. Five-year follow-up of a randomized multicenter trial of intensive early intervention vs standard treatment for patients with a first episode of psychotic illness: The OPUS trial. Arch Gen Psychiatry. 2008; 65(7): 762-71.

71. Singh SP. Early intervention in psychosis. Br J Psychiatry. 2010; 196(5): 343-5.

\footnotetext{
* Corresponding author:

Danijela Piskulic

Orygen

The National Centre of Excellence in Youth

Mental Health, 35 Poplar Road Parkville

3052 Victoria

Australia

Tel. + 61393422993

E-mail: danijela.piskulic@unimelb.edu.au
} 
